\title{
EL PROBLEMA DEL FUNDAMENTO DE LOS DERECHOS HUMANOS
}

\author{
Eusebio Fernández
}

Universidad Autonoma de Madrid

SUMARIO: 1. LOS DERECHOS FUNDAMENTALES DEL HOMBRE. INTRODUCCTÓN.-2. LA FUNDAMENTACIÓN DE LOS DEREC HOS DEL HOMBRE.-2.A-1. LA FUNDAMENTACIÓN IUSNATURALISTA. DEREC HOS HUMANOS Y NATURALEZA HUMANA; 2.A-2. INFLUENCIA DE LAS TEORAAS IUSNATURALISTAS EN LA HI'̈TORIA DE LOS DERECHOS huMANOS; 2.A-3. CRf́TICA A LA FUNDAMENTACIÓN IUSNATURALISTA DE LO'S DERECHOS HUMANOS.-2.B. FUNDAMENTACIÓN HISTORICISTA. LOS DERECHOS HUMANOS COMO DERECHOS HISTORICOS-2.C. FUNDAMENTACIÓN ÉTICA. DERECHOS HUMANOS Y VALORES DE DIGNIDAD H UMANA. DEREC HOS HUMANOS COMO DERECHOS MORALES. 



\section{LOS DERECHOS FUNDAMENTALES DEL HOMBRE. INTRODUCCIÓN}

La primera precisión que debo hacer al comienzo del desarrollo de este tema es una precisión de tipo terminológico, aunque generalmente expresa también una postura teórica, es decir, no se trata solamente de un problema de simples palabras. La necesidad de contar con un lenguaje preciso, coherente y bien construido es una exigencia de cualquier tipo de conocimiento científico, y, como tal, es de directa aplicación al problema de la elaboración de una Teoría de los Derechos Humanos (1), que no cuenta, hasta el momento y en su mayor parte, con una terminología concreta para referirse a su objeto de estudio (esto se ve, por ejemplo, en la vaguedad e imprecisión de muchas de las definiciones de derechos humanos) (2). De las distintas expresiones utilizadas, a lo largo de

(1) Ver ENRIOUE P. HABA, Droits de l'homme, libertés individuelles et ratiónalité juridique (Quelques remarques méthodologiques), en Archives de Philosophie du Droit, tome 25, La loi», Editions Sirey, París, 1980, pág. 327.

(2) Imprecisión que se ha ido acelerando según ha ganado cotidianidad la expresión «derechos humanos». Como ha señalado A. E. Pérez Luño «a medida que se ha ido alargando el ámbito del uso del término derechos humanos, su significación se ha tornado más imprecisa. Ello ha determinado una pérdida gradual de su significación descriptiva de determinadas situaciones o exigencias jurídico-políticas, en la misma medida en que su dimensión emocional ha ido ganando terreno", ANTONIo ENRTOUE PÉREz LUÑo, Delimitación conceptual de los Derechos Humanos en Los Derechos Humanos. Significación, estatuto jurídico y sistema, Publicaciones de la Universidad de Sevilla, 1979 , págs. 14-15. 
isu historia y en la actualidad, para referirse a esa realidad que denominamos "derechos humanos», y que son: derechos naturales, derechos innatos, derechos individuales, derechos del hombre, del ciudadano y del trabajador, derechos fundamentales, derechos públicos subjetivos, libertades fundamentales, libertades públicas (3), la expresión que me parece más adecuada y que creo mejor delimita la situación teórica actual de los derechos humanos sería «Derechos Fundamentales del Hombre». Con ella se quiere manifestar que toda persona posee unos derechos morales por el hecho de serlo y que éstos deben ser reconocidos y garantizados por la sociedad, el Derecho, y el poder político, sin ningún tipo de discriminación social, económica, jurídica, política, ideológica, cultural o sexual. Pero al mismo tiempo se quiere subrayar que esos derechos son fundamentales, es decir, que se hallan estrechamente conectados con la idea de dignidad humana y son al mismo tiempo las condiciones del desarrollo de esa idea de dignidad.

A la anterior definición es preciso añadir las siguientes matizaciones: en ningún caso la idea de que existen unos derechos fundamentales que todo hombre posee implica reivindicar una tabla interminable de derechos sin ningún tipo de control en su reconocimiento, sino que se refiere solamente, y no es poco, a los derechos más esenciales en relación con el pleno desarrollo de la dignidad humana.

Además, paralelamente a la posesión de los derechos fundamentales existen también deberes y obligaciones fundamentales en relación con ellos (4). Cada derecho implica también un deber, así la libertad de prensa implica el deber de expresar la verdad e informar verazmente, los derechos políticos el deber de participación ciudadana y política responsable, el derecho a la vida y a la integridad física y moral el deber de respetar la vida y la integridad de

(3) Es obvio que detrás de cada terminología se albergan concepciones jurídico-políticas distintas. Ver. Joś́ CASTAN TOBEN̂A, Los Derechos del Hombre, Ed Reus, Madrid, 1976, 2.: ed., pág. 9 y sigs.; GREGoRIo PECEs-BARBa, Derechos Fundamentales, Editorial Latina Universitaria, Madrid, 1980, págs. 13 y sigs.; ANTONIo ENRIONE Pérez LuÑo, Delimitaciön conceptual de los Derechos Humanos, en aLos Derechos Humanos. Significación, estatuto jurídico y sistema», cit., págs. 22 y sigs., y MANUEL ATIENZA, Derechos naturales o derechos humanos: un problema semántico, en "Política y derechos humanos», Fernando Torres editor, Valencia, pág. 17 y sigs.

(4) Así, por ejemplo, el artículo primero de la Devlaración Universal de Derechos Humanos (10 de diciembre de 1948) señala: *Todos los seres humanos nacen libres e iguales en dignidad y derechos, y dotados como están de razón y conciencia, deben comportarse fraternalmente los unos con los otros.» 
nuestros semejantes, etc. Este importante nexo entre los derechos y deberes humanos no debe ser pasado por alto (5).

Tampoco debe olvidarse que el ejercicio de los derechos fundamentales ya reconocidos no es ilimitado, sino que puede ser restringido en defensa de la dignidad, la seguridad, la libertad o la simple convivencia social (6), aunque estas restricciones, para que no resulten arbitrariedades del poder políttico, deben ser reguladas jurídicamente (7).

A pesar de la aparente simplicidad de la idea de los derechos fundamentales del hombre, mayormente admitida y esgrimida, su realización práctica ha presentado y sigue presentando enormes didicultades (no hay que olvidar que la historia del reconocimiento y protección de los derechos humanos es muy inferior en el tiempo a la historia de los no-derechos humanos). La época contemporánea ha conocido y conoce, junto a las Declaraciones de derechos humanos más auténticas, nobles, amplias y solemnes, las más brutales violaciones y transgresiones (8), y ello tiene una explicación bastante obvia, que es la siguiente: mientras la posesión y el ejercicio de los derechos fundamentales corresponde al hombre y a los grupos sociales, su reconocimiento, garantía y condiciones para su efectiva puesta en práctica en el sentido jurídico-político atañe a los distintos Estados (poder político, instituciones, grupos de presión, etcétera). Así, el poder político refleja muchas veces esta doble cara de garante y transgresor de los derechos humanos fundamentales. De aquí se puede deducir de manera bastante justificada que mientras el poder ilimitado e incontrolado es el peor enemigo y la negación de los derechos humanos (las constataciones históricas y actuales son numerosas y variadas), la única salida aceptable está del lado de la regulación del poder a través de, y subordinado a, la ley y el Derecho: en la realización del Estado de Derecho.

Para finalizar esta breve introducción añadiré que la defensa de los derechos humanos fundamentales se presenta como un auténtico

(5) Ver José Castán Tobeñas, Los Derechos del Hombre, cit., pág. 124.

(6) Ver GREgorio PeCes-BARBa, Derechos Fundamentales, cit., pág. 107 y sigs.

(7) Así, por ejemplo, el artículo 53.1 de la Constitución Española señala: *Los derechos y libertades reconocidos en el Capítulo segundo del presente título vinculan a todos los poderes públicos. Sólo por ley, que en todo caso deberá respetar su contenido esencial, podrá regularse el ejercicio de tales derechos y libertades, que se tutelarán de acurdo con lo previsto en el artículo 161.1. a.".

(8) Ver Clara Barretro, Derechos Humanos. Declaraciones solemnes, continuas violaciones, Aula Abierta Salvat, Salvat Editores, Barcelona, 1981, páginas 4 y sigs. 
reto moral de nuestro tiempo, la piedra de toque de la justicia del Derecho y de la legitimidad del Poder (para muchos Estados la simple mención a los derechos humanos les resulta, felizmente, un molesto compañero de viaje) y el procedimiento garantizador de la dignidad de los seres humanos contra todo tipo de alienación y manipulación (política, cultural, económica, etc.). Por estas razones no es extraño que para muchos estudiosos de este importante y complejo tema, la teoría de los derechos humanos se presente como la «plasmación histórica de las exigencias contemporáneas de justicia» (9).

\section{LA FUNDAMENTACIÓN DE LOS DERECHOS DEL HOMBRE}

La indagación sobre la fundamentación de los derechos del hombre se refiere al problema de buscar una justificación racional (ni emotiva, ni intuitiva...) a dichos derechos. Tanto en la historia de los derechos humanos fundamentales como en la actualidad se han presentado varios tipos de justificaciones que aquí pueden ser sintetizados en tres esenciales:

1. Fundamentación iusnaturalista (consiste en la consideración de los derechos humanos como derechos naturales).

2. Fundamentación historicista (consideración de los derechos humanos como derechos históricos).

3. Fundamentación ética (consideración de los derechos humanos como derechos morales).

Como tendremos oportunidad de ver a lo largo de este trabajo las dos primeras se encuentran enfrentadas en sus aspectos más relevantes, mientras la tercera puede tener algún rasgo común con las otras dos y se presenta aquí como una postura superadora de ambas, menos problemática $\mathrm{y}$, creo, más correcta.

A las dos primeras fundamentaciones se refirió J. MARITAIN en el prólogo a la obra «Los Derechos del Hombre», fruto de la investigación que la UNESCO llevó a cabo en 1947 sobre los problemas teóricos que suscitaba la que un año más tarde iba a aparecer como Declaración Universal de Derechos del Hombre (ONU, 1948). En dicha introducción escribía MARITAIN que la aceptación o el rechazo de la ley natural como fundamento de los derechos del hombre

(9) Alejandro Llano «Presentación» al libro colectivo de A. LLANo, J. BaLLesteros, J. Chozas, A. C. Pereira-Menaut y J. DE Lucas, Etica y Política en la sociedad democrática, Espasa-Calpe, Madrid, 1981, pág. 14. 
dividía en dos grupos opuestos las opiniones sobre dicho fundamento:

«Para los primeros, el hombre, en razón de las exigencias de su esencia, posee ciertos derechos fundamentales e inalienables anteriores (por su naturaleza) y superiores a la sociedad, y por ella misma nace y se desarrolla la vida social, con cuantos deberes y derechos implica. Para los segundos, el hombre, en razón del desarrollo histórico de la sociedad se ve revestido de derechos de continuo variables y sometidos al flujo del devenir y que son el resultado de la sociedad misma, a medida que progresa a compás del movimiento de la historia.»

Para J. Maritain el contraste entre ambas posturas "es irreductible y no admite conciliación en el plano teóricon. Sin embargo, él mismo apunta una posibilidad de conciliación, cuando escribe "podría, empero, atenuarse algo, siempre y cuando que por los partidarios de la ley natural se subraya que, si bien ciertos derechos fundamentales responden a una exigencia inicial de esta ley, y otros derechos a una exigencia posterior e incluso a un simple anhelo de esta última, nuestro conocimiento de unos y otros queda en todo caso sometido a un desarrollo lento y azaroso, por lo cual sólo emergen como reglas de conducta reconocidas a medida y en virtud del progreso de la conciencia moral y del desarrollo histórico de las sociedades; y siempre y cuando que por los adversarios de la ley natural se recalcara que, si bien hay derechos que aparecen como función de la evolución de la sociedad, en cambio otros derechos más primitivos aparecen como función de la misma existencia de la sociedad» (10).

Esta posibilidad de conciliación a la que se refiere J. MarITAIN será tenida bastante en cuenta a la hora de elaborar lo que aquí voy a defender como tercera postura: la fundamentación ética.

(10) J. Maritafn, Prólogo a Los Derechos del Hombre, Editorial Laia, Barcelona, 1973, trad. de Margarita Melken, Margarita Villegas de Robles, Margit Freuk de Alatorre, Manuel Sánchez Sarto, Antonio Alatorre y Teodoro Ortiz, página 26. 


\section{A-1. La fundamentación iusnaturalistta. Derechos humanos y na- turaleza humana}

La fundamentación iusnaturalista de los derechos humanos fundamentales es sin duda las más conocida y la de mayor tradición histórica; pero también es la que plantea más problemas teóricos de aceptación por parte de alguna de las más importantes corrientes contemporáneas de Filosofía y Teoría del Derecho. Los problemos a que me refiero tienen como punto de partida el viejo problema de la ley natural y el mismo concepto de Derecho Natural.

La justificación iusnaturalista de los derechos fundamentales del hombre se deriva directamente de la creencia en el Derecho natural y, por tanto, de la defensa del iusnaturalismo, como teoría que fundamenta y explica la existencia del derecho natural (11). Como ha escrito NORBERTo BoBBIo el iusnaturalismo es «aquella corriente que admite la distinción entre derecho natural y derecho positivo y sostiene la supremacía del primero sobre el segundo" (12). Pues bien, todas las fundamentaciones iusnaturalistas de los derechos humanos se caracterizan básicamente por estos dos rasgos: la distinción entre derecho natural y derecho positivo y la superioridad del derecho natural sobre el derecho positivo.

Partiendo de que el Derecho natural consiste en un ordenamiento universal deducido de la propia naturaleza humana, de ahí se derivan derechos naturales como "derechos que ostenta la persona como reflejo subjetivo de un orden normativo natural» (13), es decir, la fundamentación de esos derechos se encuentra en el derecho natural, no en el derecho positivo. Pero, además, esos derechos naturales son anteriores y superiores al Derecho positivo, y por tanto inalienables.

Al hablar de la fundamentación iusnaturalista de los derechos fundamentales del hombre voy a distinguir dos tipos, que expresan a su vez una distinción generalmente admitida entre Derecho natural ontológico y Derecho natural deontológico. El Derecho natu-

(11) Ver ANTONIO-ENRIQUe PEREZ LUÑo, Iusnaturalismo y positivismo juridico en la Italia moderna, Publicaciones del Real Colegio de España en Bolonia, Zaragoza, 1971, pág. 33.

(12) NORBERTO BOBBIo, Giusnaturalismo e positivismo giuridico, Edizioni di Comunitá, Milano, 1977, 3 ed., pág. 127. Hay trađucción castellana de ERNEsto GARZón VALDÉs, en "El problema del positivismo jurídico», Editorial Universitaria de Buenos Aires, 1965, pág. 68.

(13) ANTONIO FERNÁNDEZ-GaLIANo, Derecho Natural. Introducción filosofica al Derecho, Sección de Publicaciones de la Facultad de Derecho de la Universidad Complutense, Madrid, 1974, pág. 133. 
ral ontológico se presenta como «ciencia del ser» del derecho, mientras el derecho natural deontológico aparece como un conjunto de valores "que determinan el carácter de obligación del derecho, y que constituyen su medida" (14) ("un criterio de valoración moral del Derecho"), o también como principios jurídicos que legitiman el derecho positivo y a los que éste debe estar subordinado («una traducción en términos jurídicos de los valores morales") (15).

El Derecho natural ontológico es el defendido por las teorías iusnaturalistas tradicionales y se ejemplifica históricamente en el iusnaturalismo greco-romano, el iusnaturalismo escolástico medieval, el iusnaturalismo racionalista y, en la época contemporánea, por la corriente neotomista. El Derecho natural deontológico tiene varios representantes en la Filosofía del Derecho contemporáneo y, entre otros, podríamos citar a ALE'SSANDRo PASSERIN D'ENTREVES, Hans Welzel (16) y Frede Castberg (17).

Esta aclaración sobre los dos tipos de Derecho natural tiene plena justificación cuando la aplicamos a las distintas fundamentaciones de los derechos humanos de signo iusnaturalista. Por ello en lo que sigue voy a utilizar la distinción entre fundamentación iusnaturalista tradicional, que correspondería al Derecho natural ontologico, y fundamentación iusnaturalista atenuada, que correspondería al Derecho natural deontológico. Es obvio que las características que separan una y otra fundamentación iusnaturalista, lo mismo que uno y otro Derecho natural, son relevantes y dignas de ser tenidas en cuenta.

2.A-2. Influencia de las teorias iusnaturalistas en la historia de los derechos humanos

La fundamentación iusnaturalista de los derechos humanos fundamentales cuenta con el apoyo de un variado y numeroso conjun-

(14) A. Passerin D'ENTREves, El Derecho Natural, en la obra colectiva «Crítica del Derecho Natural», Introducción y traducción de Elías Díaz, Ed. Taurus, Madrid, 1966, págs. 197-198; el mismo autor, La noción de Estado, Ediciones Euroamérica, Madrid, 1970, trad. de Antonio Fernández Galiano, pág. 251. Ver también Elfas Díaz, Sociología y Filosofía del Derecho, Ed. Taurus, Madrid, 1980, págs. 266 y sigs.

(15) A. Passerin D'Entreves, Derecho Natural, Ed. Aguilar, Madrid, 1972, trad. de M. Hurtado Bautista, pág. XII y págs. 150 y sigs.

(16) Hans Welzel, Introducción a la Filosofía del Derecho. Derecho Natural y justicia material, Ed. Aguilar, Madrid, 1971, trad. de Felipe González Vicén.

(17) Frede Casberg, La Philosophie du Droit, Ed. A. Pedone, París, 1970, págs. 119 y sigs. 
to de ejemplos en los cuales se expresa con toda claridad la influencia de las teorías iusnaturalistas en la Filosofía de los Derechoshumanos. Así, no deben ser olvidadas las grandes aportaciones de muchas de las teorías iusnaturalistas griegas, romanas y medievales a la Prehistoria de los derechos humanos (entendiendo por prehistoria las ideas e instituciones jurídico-políticas que se relacionan y sirven de precedentes del concepto moderno de derechos humanos). Lo mismo podemos decir en cuanto a la influencia del iusnaturalismo racionalista de los siglos XVII y XVIII y del iusnaturalismo actual enmarcado en ese proceso que desde principios de siglo, pero sobre todo a partir del fin de la Segunda Guerra Mundial, se ha denominado el «renacimiento del Derecho natural», en la ya auténtica historia de los derechos humanos.

Pero uno de los momentos m6s significativos y brillantes de esa influencia, por tratarse del momento originario en que aparece el concepto de derechos humanos entendidos como derechos naturales, tiene lugar gracias a la aportación del iusnaturalismo racionalista (que siguiendo la división expresada anteriormente se trata de un tipo de iusnaturalismo ontológico) (18).

Como ha señalado A. E. PÉrez LuÑo «El concepto de los derechos humanos tiene como antecedente inmediato la noción de los derechos naturales en su elaboración doctrinal por el iusnaturalismo racionalista» (19).

(18) Ver NoRBERTo BoBbIo, Il modello giusnaturalistico, en N. Bobbio y M. BovEro, Societá e stato nella filosofía política moderna, Il Saggiatore, Milano, 1979, págs. 17 y sigs.

(19) ANTONIo ENRIQUe PÉrez LUÑo, Delimitación conceptual de los derechos humanos, en la obra colectiva de José Luis Cascajo Castro, Benito de Castro Cid, Carmelo Gómez Torres y Antonio Enrique Pérez Luño, "Los derechos humanos. Significación, estatuto jurídico y sistema», Publicaciones de la Universidad de Sevilla 1 1979, pág. 32.

Sin embargo, no se puede olvidar, como recuerda A. E. Pérez Luño, la aportación importante al tema, de los teólogos y juristas españoles de los siglos XVI y XvII. «Durante los siglos XVI y XVII -escribe- una serie de teólogos y juristas de la Escuela española, que en gran medida representó un esfuerzo de adaptación del iusnaturalismo escolástico medieval a los problemas de la modernidad, prestaron una contribución decisiva a la afirmación de los derechos humanos desde diversos ángulos. Así se halla ya en Francisco Suárez, antes que en Hobbes y Wolff, una clara delimitación del concepto de derecho natural subjetivo a partir de su conocida distinción entre el derecho como norma y el derecho como poder moral ((ius utile); a la vez que se alude, al igual que como se ha dicho luego haría Grocio, a algunos derechos de derecho natural como el de la libertad, el de propiedad común o privada de los bienes, etcétera.

Es altamente significativo que fuera un jurista español del siglo Xvi, Fer- 
¿Cómo tuvo lugar el paso de una teoría del Derecho Natural (esencialmente abstracta como es la teoría del iusnaturalismo racionalista) a una teoría de los derechos naturales concretos que va a desembocar en las Declaraciones de derechos del siglo XVIII?

La contestación hay que buscarla en el nuevo significado que tiene el Derecho natural para el iusnaturalismo racionalista y que le diferencia sustancialmente de todas las teorías iusnaturalistas anteriores. Como ha apuntado Alessandro Passerin D'EnTreves «La moderna teoria del Derecho natural no era, hablando con propiedad, una teoría del Derecho objetivo, sino una teoría de los derechos subjetivos. Se ha producido un cambio importante bajo la envoltura de las mismas expresiones verbales. El ius naturale del filósofo moderno no es ya la lex naturalis del moralista medieval, ni el ius naturales del jurista romano" (20).

Habría que matizar la expresión de A. PA'sSERIN D'ENTREVES añadiendo que la teoría del Derecho natural racionalista es también una teoría del Derecho objetivo (21), sin embargo lo que más me in-

nando Vázquez de Menchaca, quien realizara una de las primeras y más claras reivindicaciones de los denechos naturales individuales. Un sector de la doctrina ha visto en él una contribución decisiva a la difusión del término iura naturalia, con el que se refirió a aquellos derechos que poseen los individuos en base al derecho natural.

Un papel nada desdeñable le corresponde al pensamiento español en la formación conceptual de los derechos humanos a partir de los derechos naturales. Este hecho se produce en el marco de las inquietudes y polémicas intelectuales que suscita en la España del XVI el descubrimiento y conquista de América...

En estas coordenadas debe situarse el esfuerzo intelectual de diversos teólogos-juristas españoles y, de modo especial, de Francisco de Vitoria y Bartolomé de las Casas, tendente al reconocimiento de unos derechos básicos, fundados en el derecho natural, a todos los hombres por el mero hecho de serlo», págs. 33-34 y notas. Ver también J. A. Maravall, La idea de tolerancia en España (siglos XVI y XVII), en "La oposición política bajo los austrias", Ed. Ariel, Barcelona, 1974, pág. 93 y sigs.; Luciano PEREÑa, La carta de los derechos humanos. Fuentes en la doctrina clásica española de la paz, y MICHEL DEVEzE, Les Droits de l'homme dans les théories des theologiens espagnols du $X V I$ e.s., ponencias presentadas al XIVe Congrés International des Sciences Historiques, San Francisco, agosto de 1975; JosÉ LUIS ABELLAN, Historia crítica del pensamiento español, tomo 2, La Edad de Oro (siglo XVI), Espasa Calpe, Madrid, 197, pág. 349 y sigs. y 527 y sigs.

(20) A. PAsserin D'EnTREves, Derecho Natural, cit., pág. 75.

(21) Ver H. GRocio, Del derecho de la guerra y de la paz, libro I, cap. I, III y IV, Editorial Reus, Madrid, 1925, traducción de Jaime Torrubiano Ripoll, tomo I, págs. 46 y 47.

A. E. Pérez Luño no se muestra de acuerdo con la idea de esta ruptura del derecho natural racionalista en relación con la tradición iusnaturalista anterior, «La imagen -escribe- de un iusnaturalismo moderno como teoría 
teresa subrayar es la nota subjetiva que marcará notablemente las concepciones iusnaturalistas de esta escuela. Creo que se puede afirmar que en el paso del Derecho natural objetivo (derecho como norma) al derecho natural subjetivo (derecho como facultad inherente al sujeto) (22) se encuentra el concepto de derechos humanos como derechos naturales subjetivos. Aquí tiene su raiz el planteamiento jurídico del concepto moderno de derechos humanos. Este paso lo encontramos, por ejemplo, en la defición que da Grocio de ius como "qualitas moralis personae competens ad aliquid juste habendum vel agendum» (De iure belli ac pacis, I, 1, 4), donde ius se ha convertido en el concepto de derecho subjetivo, es decir, en la facultad o cualidad moral de la persona que la hace apta para poseer o hacer algo justamente (23).

La influencia del derecho natural racionalista en la historia de los derechos humanos aparece en una serie de juristas y filósofos de los siglos XVIII y XVIII (24) como Grocio, PUfENDORF, SPINOZA,

de los derechos naturales subjetivos, opuesto a la tradición iusnaturalista clásica y medieval, en tanto que teoría de la ley natural objetiva, es esquemática y simplista, y no halla reflejo en los escritores de la época», y "son manifiestas las analogías existentes entre el concepto tomista de la ley natural y la noción moderna de los derechos naturales», en "Delimitación conceptual de los derechos humanos», cit., págs. 35 y 37. A pesar de las razonables matizaciones de A. E. Pérez Luño, sobre todo las contenidas en el primer texto citado, es innegable que el concepto de Derecho Natural del iusnaturalismo racionalista ha sufrido importantes variaciones en relación con la teoría tradicional clásica y medieval. No hay más que comparar el concepto de ley natural de Santo Tomás de Aquino con el de Derecho Natural de Grocio para darse cuenta de que quizá las diferencias sean mayores que las analogías (que también existen).

(22) «A partir de Grocio - ha escrito Guido Fassó- el Derecho Natural va a ser como una norma humana puesta por autonomía y la actividad del sujeto, libre de todo presupuesto objetivo (y en particular teológico) y explicable mediante la razón, esencial instrumento de la subjetividad humana. Una confirmación de ello ha sido vista por muchos, para no decir por todos, en la trasposición de la visión iusnaturalista de la norma del Derecho Natural objetivo, a la facultad inherente al sujeto, a los derechos naturales subjetivos, o derechos innatos, y en el correspondiente iusnaturalismo, por el que el orden jurídico - político se entiende por medio del contrato- por la libre voluntad de los sujetos, antes que por la naturaleza o por una voluntad trascendente», "Historia de la Filosofía del Derecho», tomo 2, Ediciones Pirámide, Madrid, 1979, trad. de F. J. Lorca Navarrete, pág. 79.

(23) Ver Michel Villey, Lecons d'Histoire de la Philosophie du Droit, Ed. Dalloz, París, 1962, págs. 221 y sigs.; "La formation de la pensée juridique moderne», Les Editions Montchretien, París, 1975, págs. 627 y «Philosophie du droit», T. 1, Ed. Dalloz, París, 1975, pág. 153 y sigs.

(24) Ver Norbento BoBbro, Il modello giusnaturalistico, cit., pág. 18 y 
HobBes, Locke, Rousseau, Wolf F o Kant. En todos ellos lo que en la terminología contemporánea llamamos derechos humanos se expresa como derechos naturales, cuya frente se encuentra en el derecho natural. También en todos ellos la idea de los derechos naturales aparece estrechamente conectada con la teoría del contrato social (por esta teoría se va a explicar el "origen» de la sociedad y del poder político a través del paso del estado de naturaleza a la sociedad civil y política y al mismo tiempo va a servir como defensa de una nueva legitimación o fundamentación de esa sociedad civil y política basada, a su vez, en la idea del consenso (25).

También la influencia iusnaturalista se hace notar muy profundamente en las Declaraciones de Derechos de los siglos XVIII. Piénsese en la Declaración de Derechos de Virginia (12 de junio de 1776) (26), la Declaración de Independencia de los Estados Unidos (4 de julio de 1776) (27), o la Declaración de los Derechos del Hombre y del Ciudadano (26 de agosto de 1789) (28).

Para el iusnaturalismo ontológico contemporáneo (fundamentación iusnaturalista tradicional) los derechos humanos se presentan

A. Passerin D'EnTreves, Una teoría de los derechos naturales, cap. III de "Derecho natural», cit., págs. 59 y sigs.

(25) Ver N. BOBвIo y M. BOVERo, Societá e stato nella filosofia política moderna, cit., pág.s 49 y sigs.

Ver también la primera parte de mi trabajo Contrato social y Etica, en prensa.

(26) "Que todos los hombres son por naturaleza igualmente libres e independientes y tienen ciertos derechos innatos, de los que, cuando entran en estado de sociedad, no pueden privar o desposeer a su posteridad por ningún pacto, a saber: el goce de la vida y de la libertad, con los medios de adquirir y poseer la propiedad y de buscar y obtener la felicidad y la seguridad.»

(27) "Cuando en el curso de los acontecimientos humanos, se hace necesario para un pueblo disolver los vínculos políticos que lo han ligado a otro y tomar entre las naciones de la tierra el puesto, separado e igual, a que las leyes de la naturaleza, y el Dios de esa naturaleza, le dan derecho, un justo respeto al juicio de la humanidad le obliga a declarar las causas que lo impulsan a la separación.»

(28) «Los representantes del pueblo francés, constituidos en Asamblea Nacional, considerando que la ignorancia, el olvido o el desprecio de los derechos del hombre son las únicas causas de los males públicos y de la corrupción de los gobiernos, han decidido exponer, en una declaración solemne, los derechos naturales, inalienables, y sagrados del hombre...

Los textos de las tres últimas notas están tomados de Textos básicos sobre derechos humanos, Edición preparada por Gregorio Peces-Barba Martínez y Liborio Hierro Sánchez-Pescador, Sección de Publicaciones e Intercambio de la Facultad de Derecho de la Universidad Complutense, Madrid, 1973, págs. 75, 80 y 87 , respectivamente. 
como derechos naturales, cuya justificación racional conduce necesariamente al concepto de ley natural y derecho natural (29).

Las tres características más relevantes de esta fundamentación de los derechos humanos serían las siguientes:

1. El origen de los derechos naturales no es el derecho positivo, sino un tipo de orden jurídico distinto al Derecho positivo: el orden jurídico natural. Como señaló J. MaRITAIN «se trata de establecer la existencia de derechos naturales inherentes al ser humano, anteriores y superiores a las legislaciones escritas y a los acuerdos entre los gobiernos, derechos que no le incumbe a la comunidad civil el otorgar, sino el reconocer y sancionar como universalmente valederos, y que ninguna consideración de utilidad social podría, ni siquiera momentáneamente, abolir o autorizar su infracción» (30).

2. Tanto el orden jurídico natural como los derechos naturales de él deducidos son expresión y participación de una naturaleza humana común y universal para todos los hombres. Como ha escrito ANTONIO FERNÁNDEZ-Galiano "se entiende por derechos naturales aquellos derechos de los que es titular el hombre no por graciosa concesión de las normas positivas, sino independientemente de ellas y por el mero hecho de ser hombre, de participar de la naturaleza humana» (31).

(29) Así, para J. Maritain «toda justificación racional de la idea de los derechos del hombre, así como de la idea del derecho en general, exige que hallemos en sus verdaderas connotaciones metafísicas, en su dinamismo realista y en la humildad de sus relaciones con la naturaleza y la experiencia, la noción de la ley natural, desfigurada por el racionalismo del siglo xvIII. Nos percatamos entonces de que determinado orden ideal, arraigado en la naturaleza del hombre y de la sociedad humana, puede imponer exigencias morales, por doquier válidas en el mundo de la experiencia, de la historia y del hecho, y crear, por igual para la conciencia y para la ley escrita, el principio permanente y las normas primeras y universales del deber", en "Acerca de la filosofía de los derechos del hombre», en "Los derechos del hombre», cit. página 113.

(30) J. Maritatn, Acerca de la filosofía de los derechos del hombre, cit., pág. 116. En su obra Los derechos del hombre y la ley natural escribe «La verdadera filosofía de los derechos de la persona humana descansa, pues, - sobre la idea de la ley natural», Editorial La Pléyade, Buenos Aires, 1972, trad. de Héctor F. Miri, pág. 71; y en otra obra suya El hombre y el Estado señala «El fundamento filosófico de los derechos del hombre es el derecho natural», Editorial Guillermo Kraft, Buenos Aires, 1956, trad, de Manuel Gurrea, pág. 98 , ver también págs. 102 y 114 y sigs.

Sobre la filosofía política y social de J. Maritain, ver la obra de Gregorio Peces-Barba, Persona, sociedad, Estado. Pensamiento social y político de Maritain, Editorial Cuadernos para el Diálogo, Madrid, 1972.

(31) ANTONIo FERNÁNDEZ-Galiano, Derecho Natural, Introducción filosófica al derecho, cit., pág. 134. 
3. En último lugar, y por lo que se refiere a la existencia de estos derechos, «los derechos humanos existen y los posee el sujeto independientemente de que se reconozcan o no por el Derecho positivo" (32).

En cuanto a la fundamentación iusnaturalista atenuada o iusnaturalismo deontológico contemporáneo, los derechos humanos se fundamentan también en el Derecho Natural, sin embargo, se refiere a un Derecho Natural que más que tratarse de un orden jurídico (distinto al Derecho positivo) se trata, como expresa FrEDE CASTBERG, de "principios jurídicos 'suprapositivos' y objetivamente válidos", de «juicios de valor de validez general y postulados - normas generales-, que parecen tener un fundamento suficiente en la naturaleza humana» (33).

Para este autor, cuando consideramos que los derechos del hombre deben ser respetados por el orden jurídico estamos expresando «una idea puramente iusnaturalista», "la convicción de que los derechos del hombre están fundados sobre un derecho por así decir superior a las disposiciones del derecho positivo" (34).

Otros representantes de esta fundamentación iusnaturalista atenuada no se muestran partidarios de la universalidad ni de la inmutabilidad del Derecho Natural, sino de su historicidad, de acuerdo con la naturaleza histórica del hombre; sería el caso de LuIs LEGAZ Lacambra y Antonio EnRiQue Pérez LuÑo.

Para el primero «es indiscutible que los derechos humanos son derechos naturales y que en la existencia de estos consiste la realidad del Derecho natural», "los derechos humanos así formulados pueden aún ser considerados «derechos naturales», pero en función de la naturaleza histórica del hombre, y que el sistema iusnaturalista a que responde esa formulación está transido de historicidad

Para José Castán Tobeñas, quien parte de una fundamentación inspirada en la tradición iusnaturalista del humanismo cristiano, se pueden definir los «llamados derechos del hombre como aquellos derechos fundamentales de la persona humana - considerada tanto en su aspecto individual como comunitario- que corresponden a éste por razón de su propia naturaleza (de esencia, a un mismo tiempo, corpórea, espiritual y social), y que deben ser reconocidos $\mathrm{y}$ respetados por todo Poder $\mathrm{y}$ autoridad $\mathrm{y}$ toda norma jurídica positiva, cediendo, no obstante, en su ejercicio ante las exigencias del bien común", en Los derechos del hombre, págs. 13-14; ver también las páginas 9,12 y 121 .

(32) ANTONo FERnández-Galiano, Derecho Natural. Introducción filosófica al Derecho, cit., pág. 150.

(33) Frede CASTBERG, La Philosophie du Droit, cit., págs. 121 y 127.

(34) Frede Castberg, La Philosophie du Droit, cit., ppág. 138. 
$\mathrm{y}$, por lo mismo, no parece adecuado asignarle una universalidad que no responde a la variedad de situaciones humano sociales que se dan incluso en un mismo momento de la historia» (35).

También para ANTONIo ENRIQUe PÉREz LUÑo, cuya postura vere mos más tarde, la fundamentación apropiada de los derechos humanos debe ser una fundamentación iusnaturalista (36).

\section{A-3. Crítica a la fundamentación iusnaturalista de los derechos humanos}

Las mismas críticas que se han hecho al concepto de Derecho natural, referidas tanto al sustantivo como al adjetivo, son aplicables también al concepto de derechos humanos como derechos naturales (37).

1. En primer lugar, y por lo que respecta al sustantivo «derechos» en la expresión «derechos naturales», hay que tener en cuenta que los derechos naturales solamente pueden ser considerados auténticos derechos en el sentido técnico-jurídico del término, cuando se encuentran reconocidos en una norma jurídica de Derecho positivo; mientras esto no ocurra nos encontramos ante valores, intereses, objetivos y deseos humanos más o menos necesarios, importantes o fundamentales.

Por tanto, cuando los partidarios de la fundamentación iusnaturalista nos hablan de derechos naturales anteriores y superiores al derecho positivo, esto debe entenderse más bien en el sentido de exigencias éticas o principios jurídicos suprapositivos que son, efectivamente, anteriores al derecho positivo e incluso, si se quiere, superiores desde el punto de vista ético o moral, pero en ningún caso esta superioridad es una superioridad jurídica, puesto que es totalmente inadecuado pensar que el Derecho natural sea Derecho con

(35) LUIs LeGaz y LACAMBRa «Prólogo» a la segunda edición de la obra de José Castán ToBeÑas, Los Derechos del Hombre, cit., págs. III y V.

(36) Ver Antonto-Enroue Pérez Luño, Delimitación conceptual de los derechos humanos, en «Los derechos humanos. Significación, estatuto jurídico y sistema», cit., págs. 9-10, 35, 38 nota 90 y 46.

(37) Ver NoRberto BobBio, Algunos argumentos contra el Derecho Natural en "Crítica del Derecho Natural", cit., pág. 221 y sigs.; ALF. Ross, Sobre el Derecho y la Justicia, Editorial Universitaria de Buenos Aires, 1963, trad. de Genaro R. Carrió, págs. 251. sigs. 
el mismo título o en el mismo plano que el Derecho positivo (38), y menos aún que lo sea en un plano superior a éste (39).

2. En segundo lugar, la presentación y defensa de los derechos naturales como deducidos de la naturaleza humana se encuentra siempre con la necesidad de responder a la acusación de que la misma idea de naturaleza humana no es un concepto claro ni preciso, sino ambiguo y equívoco, como han demostrado repetidamente las distintas teorías iusnaturalistas, desde la Grecia clásica a la teoría contemporánea de la «naturaleza de las cosas». (40).

Además, lo correcto sería decir que los derechos naturales consisten en deducciones que hacemos a partir de juicios de valor que aplicamos a la naturaleza humana. La argumentación cambia sustancialmente si describimos este proceso como que un determinado derecho es natural ( $y$ por tanto bueno y justo) porque lo hemos derivado de lo que consideramos bueno y justo para la naturaleza humana, en lugar de decir que un derecho es natural porque proviene directamente de la naturaleza humana. Como ha señalado HANs WELZEL «Toda apelación a lo "conforme a la naturaleza" y toda integración de lo "contrario" a la naturaleza va precedida de una decisión axiológica primaria no susceptible de prueba" (41).

No es extraño, por tanto, que todas las teorías iusnaturalistas que en la historia del pensamiento filosófico-jurídico se han dado tengan en común el hecho de que el concepto de naturaleza enunciado por ellas haya sido entendido según los valores presupuestos de cada autor o corriente de pensamiento, lo que está claramente muy lejos de aquella universalidad e inmutabilidad del Derecho Natural que proclaman los iusnaturalistas.

3. En tercer lugar había que tener en cuenta - y esta matización se refiere tanto, y sobre todo, al iusnaturalismo ontológico, pero también a cierto iusnaturalismo deontológico-, que la invariabilidad, permanencia e independencia de las condiciones históricas, de los derechos naturales choca con la experiencia histórica. De la misma forma que, como escribió ALF Ross, "No hay ideología

(38) Ver N. BoBBro, Algunos argumentos contra el Derecho Natural, cit., pág. 236 y sigs.

(39) Elfas Dfaz, Sociologia y Filosofía del Derecho, cit., pág. 266.

(40) Ver Elfas Díaz, Sociología y Filosofía del Derecho, cit., págs. 299 y siguientes y Luis Legaz y LaCambra, Filosofia del Derecho, Ed. Bosch, Barcelona, 1979, págs. 206 y sigs.

Ver también NoAM ChOMSKy y Michel Foucault, La naturaleza humana: Justicia contra poder, en "La Filosofía y los problemas actuales", Editorial Fundamentos, Madrid, 1981, págs. 145 y sigs., trad. de Agustín Gil Lasierra. 
que no pueda ser defendida recurriendo a la ley natural" (42), también nos encontramos que a lo largo de la historia de los derechos humanos se han presentado como derechos naturales contenidos, a veces, opuestos. El contenido y número de los derechos humanos, como la importancia concedida a cada uno de ellos ha cambiado y cambia, «La lista de los derechos humanos se han modificado y está modificándose, siguiendo el cambio de las condiciones históricas, es decir, de las necesidades, de los intereses, de las clases en el poder, de los medios disponibles para su realización, de las transformaciones técnicas, etc.». Ello viene a probar que si exceptuamos el derecho a la vida y a la integridad física y moral (lo que es también matizable ,aunque se trate de derechos fundamentalísimos, porque no es raro encontrar individuos, ideologías, sociedades y culturas y grupos de poder políttico que han admitido y admiten la esclavitud, la aniquilación moral y hasta física del considerado como «enemigo" por no compartir sus ideas y creencias, la pena de muerte o el aborto. Evidentemente todos estos hechos nos dan pie a insistir con más fuerza en el fundamento ético inviolable de los más esenciales derechos humanos), no "existen derechos fundamentales por su naturaleza. Lo que parece fundamental en una época o en una cierta civilización, no es fundamental en otras épocas y en otras culturas. No puede haber —añade BoBBIo- un fundamento absoluto de derechos históricamente relativos» (43). En definitiva, el argumento de la historicidad del Derecho Natural y de los derechos naturales es difícilmente rebatible.

4. En cuanto a admitir, como hacen los iusnaturalistas, que «los derechos humanos existen y los posee el sujeto independientemente de que se reconozcan o no por el Derecho positivo" (FERNANDEZ-GALIANO), sin exigir su reconocimiento por parte de una norma de derecho positivo es una verdad a medias e insuficiente e ingenuo desde el mínimo punto de vista de la necesaria efectividad y ejercicio de los derechos fundamentales del hombre. Mientras los derechos humanos no estén reconocidos y amparados por el ordenamiento ju-

(41) HANS WELzEL, Derecho Natural y Justicia material. Introducción a la Filosofía del Derecho, cit., pág. 11 y 254.

(42) AlF Ross, Sobre el Derecho y la Justicia, cit., pág. 254.

(43) Las dos últimas citas son del artículo de N. BoBBio, L'illusion du fondement absolu, en "Le fondement des droits de l'homme», Actes des entretiens de L'Aquila (14-19 septembre 1964), Institut International de Philosophie, La Nuova Italia, Firenza, 1966, pág. 5. Ver también en la misma obra JosEP H MOREAU, Les droits de thomme: déclarations et fondement, pág. 130-131. 
rídico su existencia plena, garantizada jurídicamente, aún no habrá tenido lugar (44).

5. Finalmente, frente a la idea defendida por los iusnaturalistas de que la única fundamentación posible de los derechos humanos es la fundamentación iusnaturalista, ya que, según ellos, la afirmación de que existen «algunos derechos esenciales del hombre en cuanto tal... no se puede separar del reconocimiento previo $\mathrm{y}$ necesario de un derecho natural; natural en cuanto distinto del positivo y, a su vez preliminar y fundamental respecto a éste» (45), considero más adecuado decir que la fundamentación iusnaturalista es una de las posibles fundamentaciones de los derechos humanos, pero en ningún caso la única. En esta, creo que errónea, identificación entre fundamentación de los derechos humanos y necesaria fudamentación iusnaturalista ha caído, por ejemplo, ANTONIO ENRIQUE PÉREZ LuÑo en su interesante trabajo «Delimitación conceptual de los derechos humanos", cuando después de exponer su definición (46) de los derechos humanos añade que «La definición propuesta pretende conjugar las dos grandes dimensiones que integran la noción general de los derechos humanos, esto es, la exigencia iusnaturalista respecto a su fundamentación y las técnicas de positivación y protección que dan la medida de su ejercicio" (47).

También GREGORIO ROBLES, desde posturas manifiestamente no

(44) Ver Gregorio Peces-Barba, Derechos Fundamentales, cit., pág. 28, y ANTONIo FERnANDEZ-Galiano, Derecho Natural. Introducción filosófica al Derecho, cit., pág. 115.

(45) Ver F. Battaglia, Declaraciones de Derechos, en "Estudios de Teorfa del "Estado", Publicaciones del Real Colegio de España en Bolonia, Madrid, 1966, trad. de Elías Díaz y Pedro de Vega, prólogo de L. Legaz Lacambra, pág. 175.

(46) Contando, además, con que la definición propuesta por A. E. Perrez Luño en su trabajo: «los derechos humanos aparecen como un conjunto de facultades e instituciones que, en cada momento histórico, concretan las exigencias de la dignidad, la libertad y la igualdad humanas, las cuales deben ser reconocidas positivamente por los ordenamientos jurídicos a nivel nacional e internacional» (pág. 43), no me parece una definición iusnaturalista, al menos en el sentido tradicional del iusnaturalismo. Las referencias a «cada momento histórico» y a las "exigencias de la dignidad, la libertad y la igualdad humana" creo que son más asimilables a lo que yo entiendo por fundamentación ética de los derechos humanos que a las cotidianas fundamentaciones iusnaturalistas.

(47) ANTONIo ENRIQUe PéREZ LuÑo, Delimitación conceptual de los derechos humanos, en "Los derechos humanos. Significación, estatuto jurídico y sistema», pág. 46, también págs. 9 y 10.

Véase la recensión crítica de Manuel Atienza a esta obra, elaborada con José Luis Cascajo, Benito de Castro Cid y Carmelo Gómez Torres, en «Sistema» 37, junio de 1980 , págs. 146 y sigs. 
iusnaturalistas (48), identifica ambas fundamentaciones cuando escribe que «La teoría de los derechos humanos se enmarca necesariamente en la corriente del pensamiento iusnaturalista», con el fin de negar la posibilidad de elaborar una teoría de los derechos humanos, argumentando que «habiendo fracasado las bases epistemológicas sobre las que éste (el pensamiento iusnaturalista) se apoya, la teoría de los derechos humanos carece asimismo de una consistente base gnoseológica» (49). La tesis defendida por GREGORIO RoBLES me parece parcial, en el sentido de que una cosa es partir de dos hechos ciertos como son el origen iusnaturalista (y concretamente del iusnaturalismo racionalista) del concepto moderno de los derechos humanos y del fracaso de las bases epistemológicas del iusnaturalismo, pero otra cosa bien distinta es deducir de ahí que toda fundamentación de los derechos humanos tenga que ser necesariamente iusnaturalista y por tanto todo intento de elaborar una consistente teoría de ellos esté abocada al fracaso.

La fundamentación ética, que más tarde desarrollaré, pretende ser también una respuesta a este tipo de críticas.

2.B. Fundamentación historicista. Los derechos humanos como derechos históricos

¿En qué consiste la fundamentación historicista de los derechos humanos? Para este tipo de fundamentación, los derechos huma-

(48) Ver Gregorio Robles, El fracaso epistemológico de la doctrina del Derecho Natural, en $\star$ Revista de la Facultad de Derecho de la Universidad Complutense, Madrid, 1978, núm. 54.

(49) GREGORIO ROBLES MORCHON, Análisis critico de los supuestos teóricos y del valor politico de los derechos humanos, en * Rivista Internazionale di Filosofia del Diritto», luglio-settembre, Milano, 1980, págs. 480 y sigs.

También señala que ael concepto de derechos humanos es un concepto político y no técnico, y no puede ser otra cosa. Y como tal concepto político está en función de la lucha política: sirve $\multimap$ puede servir- para intentar transformar la realidad o para intentar conservarla, pero no para describirla y conocerlan (pág. 480). Creo que tal «pureza metodológica y delimitación entre lo político y lo técnico es una pretensión razonable, importante y necesaria, sin embargo, también de difícil adquisición, entre otras razones, pero quizá ésta sea la más importante, por el mismo contenido de estudio de las ciencias sociales en general y del Derecho en particular. En cuanto al concepto de derechos humanos, es verdad que se trata de un concepto político, y ello porque el contexto que originó y sigue manteniendo la problemática de los derechos humanos es un contexto político necesariamente, pero, añado, no solamente político. Parte de la numerosa bibliografia que existe sobre los derechos humanos y los intentos que para su mejor análisis se llevan a cabo demuestran que es ya posible tratar este tema científicamente. 
nos manifiestan los derechos variables y relativos a cada contexto histórico que el hombre tiene y mantiene de acuerdo con el desarrollo de la sociedad.

Las diferencias con la fundamentación iusnaturalista son claras: '

1. En lugar de derechos naturales, universales y absolutos se habla de derechos históricos, variables y relativos.

2. En lugar de derechos anteriores y superiores a la sociedad se habla de derechos de origen social (en cuanto que son resultado de la evolución de la sociedad).

Para los defensores de esta fundamentación «El concepto y formulación de los Derechos Humanos se ha ido decantando a través de la historia a partir del núcleo teórico más amplio de humanidad entendida ésta no en su apoyo sentimental, sino como un proceso de autoconciencia, mediante el cual se ha objetivado la esencia del hombre como un concepto unitario y abstracto"; los derechos humanos «se fundan, no en la «naturaleza» humana sino en las necesidades humanas y en las posibilidades de satisfacerlas dentro de una sociedad»; por tanto, "la temática específica de los Derechos Humanos estará en función de los valores constituidos en una comunidad histórica concreta y de los fines que ella misma pretende realizar, siempre que se respete como principio ineludible la propia esencia de la dignidad de la persona humana como el fin de sí misma, pues de otra forma no podríamos hablar del «hombre» sino de cualquier otra cosa, aunque justa y útil» (50).

En la investigación que elaboró la Unesco, en 1947, sobre los fundamentos de la Declaración de Derechos del Hombre, la fundamentación historicista fue defendida por el filósofo italiano B. CroCE. Para este autor colocar el fundamento de los derechos humanos en la teoria del derecho natural" se ha convertido en algo filosófica e históricamente insostenible», debe abandonarse "la base lógica de dichos derechos considerados como derechos universales del hombre» y reducirlos «a lo sumo, a derechos del hombre en la historia. Esto equivale a decir que los derechos son aceptados como tales para hombres de una época particular. No se trata, por consiguiente, de demandas eternas, sino sólo de derechos históricos, manifestaciones de las necesidades de tal o cual época, e intentos de satisfacer dichas necesidades" (51).

La fundamentación historicista de los derechos humanos así con-

(50) Manuel Peris, Juez, Estado y Derechos Humanos, Ed. Fernando Torres, Valencia, 1976, págs. 135 y 137 y sigs.

(51) B. CROCE, Los derechos del hombre y la situación historica presente, en «Los derechos del hombre», cit., págs. 143 y sigs. 
siderada describe de forma bastante correcta la evolución y el desarrollo de los derechos humanos y aparece como un modelo explicativo de esa evolución mucho más realista que el modelo de fundamentación iusnaturalista, sin embargo, no hace justicia al hecho de que el concepto contemporáneo de los derechos humanos fundamentales es deudor en su origen de la fundamentación iusnaturalista, representada en los siglos XVII y XVIII por el iusnaturalismo racionalista.

Además, se deben hacer dos precisiones críticas en relación con esta fundamentación historicista.

La primera de ellas responde a la pregunta de si es tan amplia la variabilidad histórica aplicada a todos los derechos. La variabilidad histórica es bastante cierta en el caso de los derechos cívico-políticos, y en los derechos económico-sociales y culturales; pero, $i$ lo es igual en el caso de los derechos personales, como el derecho a la vida y a la integridad física y moral? En este último caso creo que nos encontramos ante un sustrato permanente, con variabilidad sólo de matices.

La segunda precisión se refiere a la consideración de los derechos humanos como satisfacción de necesidades humanas. Los derechos fundamentales concebidos así, como exigencias basadas en las necesidades humanas y en las posibilidades de satisfacerlas dentro de una sociedad, pero también como derechos, es decir, valores integrados en normas jurídicas, ¿deben reconocer y garantizar todo tipo de necesidades, ¿es ésto posible y cómo sería posible?, ¿es necesario llevar a cabo una elección entre necesidades más apremiantes y fundamentales y las menos?, ¿ de acuerdo con qué valores se hará esta elección? Parece correcto y realista contestar, generalmente, que es necesario efectuar esta elección y que los derechos humanos se referirán a las necesidades más importantes y relevantes para la vida humana.

También nos podemos hacer las siguientes preguntas en relación con la consideración de los derechos humanos como derechos históricos: los derechos humanos entendidos como derechos humanos fundamentales, ¿pueden ser relativos al mismo tiempo? Si son fundamentales, ¿ pueden ser relativos en general y en cada contexto histórico o más bien son fundamentales en un momento histórico concreto más o menos largo?

No creo que la fundamentación historicista sea capaz de contestar satisfactoriamente a estas preguntas. De todas formas, es preciso distinguir entre una visión histórica de los derechos humanos y la fundamentación historicista. La visión histórica de los derechos del 
hombre, aunque no es privativa de la fundamentación historicista (y esto es obvio, porque tal visión es inatacable, salvo que neguemos la historia) es el argumento principal utilizado por esta fundamentación. Lo que aquí nos interesa resaltar es esa utilización. Así, para Dino PASINI, «La concepción de los derechos del hombre es una concepción histórica, dinámica que implica el progresivo reconocimiento, el respeto y la tutela jurídica del hombre considerado en su integridad como individuo y persona irrepetible, como ciudadano y como trabajador y, por tanto, no sólo de los derechos personales... de los derechos civiles y políticos... sino también de los derechos económico-sociales y culturales» (52). También para T. C. VAN Boven «La noción de derechos del hombre es en gran parte el producto de la historia de la civilización humana y por tanto sujeto a evolución y modificación» (53). Esta modificación y evolución de los derechos del hombre se ejemplifica en las distintas etapas que su historia ha conocido. De comenzar siendo en sus orígenes un concepto político que engloba una serie de libertades frente al Estado (concepto propio de la etapa individualista liberal), a la concepción de derechos cívico-políticos que se ejercen en el seno del Estado (etapa de positivación y constitucionalización de los derechos del hombre) (54), para seguir con la aparición de los derechos económico-sociales y culturales como categoría de derechos humanos distinta a las otras dos anteriores (en esta última etapa el Estado actúa como promotor y garante del bienestar económico y social (55), y corresponde al Estado social de Derecho) (56).

(52) Dino Pasini, Il problema dei diritti umani nel mondo occidentale, en "I Diritti dell'uomo", Casa Editrice Dott. Eugenio Jovene, Napoli, 1979, pág. 198.

(53) THEODOR C. VAN Boven, Les critères de distinction des droits de l'homme, en "Les dimensions internationales des droits de líhomme", Unesco, París, 1978, pág. 53.

(54) Como ha escrito Antonio-Enrique Pérez Luño, «A partir del siglo xvirI se considerará que la constituciones deben contener: de una parte, una serie de reglas relativas a la organización de los poderes públicọs, y de otra, unas disposiciones que proclamen los principios fundamentales que deben inspirar el funcionamiento de todos los órganos del Estado. Estos últimos venían enunciados en las declaraciones de derechos que caracterizarán la propia naturaleza y fines del Estado", El proceso de positivación de los derechos fundamentales, en "Los Derechos Humanos. Significación, estatuto jurídico y sistema», cit., pág. 241.

(55) Ver ERNst Forsthof F, El Estado de la sociedad industrial, Instituto de Estudios Políticos, Madrid, 1975, trad. de Luis López Guerra y Jaime Nicolás Muniz, págs. 252 y sigs.

Ver también SERGIUS HESSEN, Los derechos del hombre en el liberalismo, 
2.C. Fundamentación ética. Derechos Humanos y valores de la dignidad humana. Derechos Humanos como derechos morales

Los dos tipos de fundamentación de los derechos fundamentales que hasta ahora hemos analizado pueden ser comprobados históricamente.

La fundamentación iusnaturalista, la que corresponde al ius naturalismo racionalista, de los derechos naturales del mundo moderno es evidente. Ahí están Grocio y PUfENDORF con la idea de los derechos naturales subjetivos y las Declaraciones de Derechos del siglo XVIII, en las cuales el fundamento iusnaturalista está perfectamente precisado $\mathrm{y}$ asimilado.

La fundamentación iusnaturalista contemporánea ya acarrea otro tipo de problemas, sobre todo de tipo epistemológico y desde la perspectiva de la teoría del Derecho. La fundamentación historicista, y más concretamente en lo que tiene de visión histórica, también es comprobable. El humanismo (57), y fundamentalmente, aunque no de forma exclusiva, el humanismo cristiano, y el individualismo (58) pertenecen al núcleo ideológico de la prehistoria y la historia de los derechos humanos fundamentales. Por otro lado, los valores del liberalismo (59) y sus presupuestos (libertad,

en el socialismo y en el comunismo, en «Los derechos del hombre», cit., páginas 163 y sigs.

(56) Ver Elfas Diaz, Estado de Derecho y sociedad democrática, Editorial Cuadernos para el Diálogo, Madrid, 1972, págs. 95 y sigs., y MaNUEL García PELAYo, Las transformaciones del Estado contemporáneo, Alianza Editorial, Madrid, 1977, principalmente, págs. 13 y sigs.

(57) Ver JOsÉ CASTÁN TOBENAS, Los Derechos del Hombre, cit., págs. 38 y siguientes y FELICE BATTAGLIA, Los Derechos Fundamentales del Hombre, del ciudadano y del trabajador: esencia, evolución, perspectivas futuras y Declaraciones de Derechos, en "Estudios de Teoría del Estado», cit., págs. 158 y siguientes y 176 y sigs., respectivamente.

(58) Ver Steven LuKes, El individualismo, Ediciones Península, Barcelona, 1975, trad. de José Luis Alvarez.

(59) Ver H. J. LASKI, El liberalismo europeo, Fondo de Cultura Económica, México, 1969, trad. de Victoriano Miguélez; GuIDo DE RUGGIERo, Historia del liberalismo europeo, Ediciones Pegaso, Hadrid, 1944, trad. de C. G. Posada; J. Salwyn Schapiro, Liberalismo, Ed. Paidós, Buenos Aires, 1965, trad. de Julio Ameller; Francisco López Cámara, Origen y evolución del liberalismo europeo, Universidad Nacional Autónoma de México, 1971; ANDRÉ Vachet, La ideología liberal, Ed. Fundamentos, Madrid, 1972, trad. de Pablo Fernández Albadalejo, Valentina Fernández Vargas y Manuel Pérez Ledesma; GeORGeS Burdeau, Le Libéralisme, Editions du Seuil, París, 1979 y Françors-Paul BÉnotT, La démocratie libérale, Presses Universitaires de France, París, 1978. 
igualdad moral y jurídica, propiedad y seguridad), lo mismo que las exigencias económicas, políticas y sociales nacidas como fruto de las transformaciones de la dialéctica Estado-sociedad (piénsese en las conexiones entre el Estado social de Derecho y los derechos económico-sociales y culturales (60)) y de la irrupción de un socialismo liberal (61) y democrático (62), han calado profundamente y se encuentran encarnadas en el concepto moderno y contemporáneo de los derechos humanos fundamentales.

Pero aún subyace la pregunta sobre el fundamento de los derechos humanos fundamentales. ¿En nombre de qué hablamos y defendemos esa realidad que delimitamos con el nombre de derechos humanos fundamentales?

Ni la fundamentación iusnaturalista (para la cual el fundamento de los derechos humanos estaría en el derecho natural, deducido de una naturaleza humana supuestamente universal e inmutable), ni la fundamentación historicista (cuyo fundamento estaría en la historia, cambiante y variable) responden coherentemente a esa pregunta sobre el fundamento. Creo que la fundamentación ética, que paso a exponer, lo hace de forma más satisfactoria.

La fundamentación ética o axiológica de los derechos humanos fundamentales parte de la tesis de que el origen y fundamento de estos derechos nunca puede ser jurídico sino previo a lo jurídico. El Derecho (me refiero siempre al Derecho positivo) no crea los derechos humanos. Su notable labor, sin la cual el concepto de derechos humanos no tendrá plena efectividad, está en reconocerlos, convertirlos en normas jurídicas y garantizarlos también jurídicamente.

Si toda norma, tanto moral como jurídica, "presupone» una se-

(60) Ver Antonio Truyol y SERra, Los Derechos Humanos, cit., págs. 20 y siguientes y ANTONIo ENRIQUe PÉREZ LuÑo, El proceso de positivación de los derechos fundamentales, en "Los Derechos humanos. Significación, estatuto jurídico y sistema», cit., págs. 20 y sigs.

(61) Ver Carlo Rosselli, Socialismo liberal, Editores Mexicanos Unidos. México, 1977. Véase también la introducción de Norberto Bobbio a la edición italiana de esta obra, Giulio Einaudi editore, Torino, 1979.

(62) Ver Elfas Díaz, Socialismo democrático y derechos humanos, en «Legalidad y legitimidad en el socialismo democrático», Ed Civitas, Madrid, 1978, págs. 125 y sigs.; y GREgorIo PECes-BARBA, "El socialismo y la libertad", "Socialismo y Estado de Derecho" y «Notas sobre derechos fundamentales, socialismo y Constitución", en "Libertad, poder, socialismo", Ed. Civitas, Madrid, 1979 , págs. 133 y sigs.

Sobre la evolución histórica de los derechos humanos puede consultarse la obra de Clara BarReIro BarReIro, Derechos Humanos. Declaraciones solemnes, continuas violaciones, cit., págs. 8 y sigs. 
rie de valores acerca de los fines de la vida individual, social y política, esto es aún más evidente, me parece, cuando tratamos de justificar racionalmente los derechos humanos fundamentales (63).

Por tanto, una vez supuesta la idea anterior, entiendo por fundamentación ética o axiológica de los derechos humanos la idea de que ese fundamento no puede ser más que un fundamento ético axiológico o valorativo, en torno a exigencias que consideramos imprescindibles como condiciones inexcusables de una vida digna, es decir, de exigencias derivadas de la idea de dignidad humana.

Esta creo que es la razón de ser de todos los precedentes históricos del concepto moderno de los derechos naturales, de las Declaraciones de derechos del siglo XVIII y de las Declaraciones, Pactos internacionales y textos contemporáneos, en general, referentes a los derechos humanos.

Para esta fundamentación y consiguiente concepción que defiendo, los derechos humanos aparecen como derechos morales, es decir, como exigencias éticas y derechos que los seres humanos tienen por el hecho de ser hombres $y$, por tanto, con un derecho igual a su reconocimiento, protección y garantía por parte del Poder político y el Derecho; derecho igual obviamente basado en la propiedad común a todos ellos de ser considerados seres humanos y derecho igual de humanidad independiente de cualquier contingencia histórica o cultural, característica física o intelectual, poder político o clase social (64).

(63) Soy deudor en este punto de las ideas expresadas por JosÉ HIERRo SÁNCHEZ-PESCADOR en su artículo, Normas y valoraciones, en "Teoría y sociedad. Homenaje al Prof. Aranguren», Ediciones Ariel, Barcelona, 1970, páginas 133 y 139 .

(64) Para Carlos Santiago Nino, «Los "derechos individuales" son los derechos morales que los hombres tienen no por cierta relación especial con otros hombres, ni por ocupar determinado cargo o función, ni por ciertas particularidades físicas o intelectuales, ni por las circunstancias en que un individuo puede encontrarse, sino por el hecho de ser hombres. Siendo la propiedad de ser individuo humano la circunstancia antecedente que sirve de condición suficiente de estos derechos, todos los hombres tienen un título igual a ellos (salvo que se sostuviera, como algunos partidarios de la esclavitud y del aborto han pensado, que la humanidad es una propiedad que puede presentarse en diferentes grados)», Introducción al análisis del Derecho, capítulo VII, La valoración foral del Derecho, Editorial Astrea, Buenos Aires, 1980, pág. 417.

Mi única precisión a las excelentes páginas dedicadas por Carlos Santiago NINo, a La fundamentación liberal de los derechos individuales básicos, es que una fundamentación contemporánea de los derechos humanos debe ampliarse también a los derechos ćvico-políticos y económico-sociales y culturales. 
Esta concepción de los derechos humanos fundamentales, perfectamente aceptable y aceptada en la actualidad, es la expresada por ANTONIo TRUYOL y SERRA, cuando escribe: «Decir que hay «derechos humanos» o "derechos del hombre» en el contexto histórico-espiritual que es el nuestro, equivale a afirmar que existen derechos fundamentales que el hombre posee por el hecho de ser hombre, por su propia naturaleza y dignidad; derechos que le son inherentes, y que, lejos de nacer de una concesión de la sociedad política, han de ser por ésta consagrados y garantizados» (65).

Quizá el término «derechos morales» (66) que utilizo para definir los derechos humanos fundamentales, levante alguna suspicacia. Voy a explicarlo.

Con el término «derechos morales» pretendo describir la síntesis entre los derechos humanos entendidos como exigencias éticas o valores y los derechos humanos entendidos paralelamente como derechos. El calificativo "morales» aplicado a "derechos» representa tanto la idea de fundamentación ética, como una limitación en el número y contenido de los derechos que podemos comprender dentro del concepto de derechos humanos. Según esto, solamente los derechos morales, o lo que equivale a decir los derechos que tienen que ver más estrechamente con la idea de dignidad humana pueden ser considerados como derechos humanos fundamentales. El sustantivo "derechos" expresa la idea de que los derechos humanos están a caballo entre las exigencias éticas y los derechos positivos, pero también la necesidad y pretensión de que para su "auténtica realización» los derechos humanos estén incorporados en el ordenamiento jurídico, es decir, que a cada derecho humano como derecho moral le corresponda paralelamente un derecho en el sentido estrictamente jurídico del término.

En definitiva, la fundamentación ética de los derechos humanos fundamentales se basa en la consideración de esos derechos como derechos morales, entendiendo por derechos morales el resultado de la doble vertiente ética y jurídica. Creo que esta fundamentación de los derechos humanos nos permite salir del círculo vicioso de la tradicional polémica entre iusnaturalismo y positivismo. En relación con la fundamentación iusnaturalista, porque no se queda en la simple defensa de la existencia de los de-

(65) Antonio Truyol y Serra, Estudio Preliminar a Los Derechos Humanos. Declaraciones y Convenios internacionales, cit., pág. 11.

(66) Ver H. L. A. HART, ¿Existen derechos naturales?, en «Filosofía Políticas, recopilación de Anthony Quinton, Fondo de Cultura Económica, México, 1974, trad. de E. L. Suárez, pág. 84 y sigs. 
rechos humanos, como derechos naturales, independientemente de su incorporación al derecho positivo, sino que al mismo tiempo que insiste en su especial importancia e inalienabilidad propugna la exigencia de reconocimiento, protección y garantías jurídicas plenas (67). En relación con el positivismo jurídico porque defiende la existencia de los derechos humanos aún en el caso de que éstos no se hallen incorporados al ordenamiento jurídico (en este supuesto, su existencia es parcial e incompleta, pero también es cierto que si no aceptamos esa existencia moral previa no es posible ni criticar a cualquier ordenamiento juridico porque no los reconoce ni garantiza, ni defender la necesidad de su incorporación al derecho positivo). Con ello asumo lo expresado por CARlos Santiago Nino, cuando escribe que «la existencia de los derechos individuales, en tanto derechos morales ,no está condicionada a su reconocimiento a través de ciertas normas jurídicas, ya que ellos incluyen precisamente pretensiones de que se establezcan normas jurídicas prescribiendo medios de protección de los derechos en cuestión (por ejemplo, otorgándoles jerarquía constitucional y estableciendo el control de la constitucionalidad de leyes que pudieran restringirlos, estipulando sanciones para los funcionarios que las violen, prescribiendo deberes activos para implantarlos, etc.)" (68).

La concepción de los derechos humanos que aquí postulo está muy próxima a las expresadas por Gregorio PeCES-BARBa y ANTo-

(67) El paso de los derechos humanos como valores a los derechos humanos como derechos se daría cuando se han cumplido los requisitos a que se refiere Gregorio Peces-Barba en el siguiente texto: "Las exigencias necesarias para que la filosofía de los derechos humanos se conviertan en Derecho positivo vigente en un país determinado son las siguientes:

1. Que una norma jurídica positiva las reconozca (normalmente con rango constitucional o de ley ordinaria).

2. Oue de dicha norma derive la posibilidad para los sujetos de derecho de atribuirse como facultad, como derecho subjetivo, ese derecho fundamental.

3. Que las infracciones de esas normas, y por lo tanto, el desconocimiento de los derechos subjetivos que derivan de ellas, legitime a los titulares ofendidos para pretender de los tribunales de justicia el restablecimiento de la situación y protección del derecho subjetivo, utilizando si fuese necesario para ello, el aparato coactivo del Estado.

Solamente en este caso estaremos ante la plenitud de un derecho fundamental, en «Derechos Fundamentales», cit., pág. 63.

(68) Carlos Santiago Nino, Introducción al análisis del Derecho, cit., página 418. 
Nio-ENRIQue Pérez Luño. En el primer caso, me refiero a la concepción dualista defendida por PecEs-Barba (la concepción dualista indica, para este profesor, el estudio de los derechos fundamentales desde la perspectiva de dos niveles: el nivel axiológico o Filosofía de los derechos fundamentales y el nivel jurídico o Derecho de los derechos fundamentales, que vendría dado por la «inserción de esos valores en normas jurídicas en el Derecho positivo, y la configuración de los derechos fundamentales como derechos públicos subjetivos» (69). Sin embargo, creo conveniente hacer las siguientes matizaciones a esta concepción. En primer lugar, considero que puede darse el caso de derchos fundamntales que se defiendan como tales, y lo sean realmente, y que en cambio no hayan sido incorporados al derecho positivo, es decir, no tengan la configuración, aunque sí la pretensión, de convertirse en derechos públicos subjetivos. Piénsese en el derecho a la objeción de conciencia, la desobediencia civil (si se considera como un derecho), o en general los derechos de las minorías (siempre y cuando estos supuesto derechos de las minorías no violen gravemente las reglas de un sistema jurídico-político aceptado y conformado por la mayoría. Me refiero a un sistema democrático en el cual los derechos justos de las minorías tuvieran pocas posibilidades de ser apoyados por la mayoría, y por tanto de ser incorporados al derecho positivo. Nadie podrá negar que esos derechos justos de las minorías no sean también derechos fundamentales). En segundo lugar, creo que se debe insistir en que la concepción dualista no se agota en el momento en que los valores expresados en cualquier derecho fundamental se han convertido en norma jurídica, sino que los derechos fundamentales una vez configurados como derechos subjetivos siguen expresando valores, siguen conteniendo exigencias éticas. En tercer lugar, habría que hacer hincapié en la dinamicidad de esta concepción dualista, como concepción siempre abierta a nuevas exigencias históricas. En el caso de A. E. Pérez LuÑo estoy de acuerdo con él cuando señala que «Es, precisamente, de esa idea de la dignidad

(69) Gregorio Peces-Barba, Derechos Fundamentales, cit., pág. 27. Ver también, págs. $25,26,28$ y sigs. y 83 y sigs. La definición de los Derechos fundamentales para Peces-Barba sería: "Facultad que la norma atribuye de protección a la persona en lo referente a su vida, a su libertad, a la igualdad, a su participación política o social, o a cualquier otro aspecto fundamental que afecte al desarrollo integral como persona, en una comunidad de hombres libres, exigiendo el respeto de los demás hombres, de los grupos sociales y del Estado, y con posibilidad de poner en marcha el aparato coactivo del Estado en caso de infracción», pág. 66. 
de la persona humana así como de las exigencias y necesidades ligadas a la consecución de la libertad y la igualdad de donde se derivan los derechos humanos. Estos derechos esenciales tienen un fundamento anterior al derecho positivo, esto es, preliminar y básico respecto a éste» (70). No obstante, coincidiendo con él en la idea de que el fundamento de los derechos humanos es «un fundamento anterior al derecho positivo», discrepo en que ese fundamento tenga que ser necesariamente iusnaturalista, y no simplemente de defensa de las exigencias morales de dignidad, libertad e igualdad de la persona humana.

El problema que plantea la fundamentación ética de los derechos humanos no es un problema que afecte solamente al Derecho de los Derechos Fundamentales o parte del Derecho general que tiene momo objeto de análisis y estudio el tema de los derechos humanos (71), sino que es un problema preferentemente ético ya que se trata de los valores éticos, sustrato y última referencia básica de los derechos humanos. Su discusión y tratamiento debe hacerse, como ha escrito ENRIQUE P. HABA, sobre «el plano axiológico, no sobre el de los puros hechos o del derecho positivo simplemente» (72).

Esta perspectiva axiológica sería la propia de la Filosofía de los Derechos Humanos, como primera parte de una Teoría General de los Derechos Humanos (la segunda parte de esa Teoría General estaría formada por la Ciencia de los Derechos Humanos o Derecho de los Derechos Humanos). Para la elaboración de la Filosofía de los Derechos Humanos habría que tener en cuenta no sólo las aportaciones de la Filosofía moral o ética, sino también las de la Filosofía Política (en el sentido de que la consecución de un poder político justo se halla estrechamente enlazada con el respeto, reconocimiento y garantías de los derechos humanos fundamentales y en el sentido también de que los derechos humanos pueden ser considerados, según ha apuntado Elfas Dfaz, como «el

(70) ANTONIO-ENRIOUE PÉREZ LuÑo, Introducción a Los derechos humanos. Significación, estatuto jurídico y sistema, cit., pág. 10.

(71) Sobre la Ciencia de los Derechos Humanos ver Carlos García Bauer, ¿Puede elaborarse ya una disciplina de los derechos humanos?, en Veinte años de evolución de los derechos humanos, Instituto de Investigaciones jurídicas, México, 1974, págs. 463 y sigs.; GrbGoRIo PECES-BARBA, Derechos Fundamentales, cit., págs. 86 y sigs. y BENITO DE CASTRO CID, Dimensión cientifica de los Derechos del Hombre, en Los derechos humanos. Significación, estatuto juridico y sistema, cit., págs. 47 y sigs.

(72) ENRIOUE P. HABA, Droits de l'homme, libertés individuelles et rationalité juridique (Quelques remarques méthodologiques), en "Archives de Philosophie du Droit», tome 25, "La Loi», Ed. Sirey, París, 1980, pág. 333. 
criterio de legitimidad del poder político" (73) y la Filosofía del Derecho (ya que el contenido de la Teoría de la Justicia o axiología jurídica, que debe animar y fortalecer la lucha por el Derecho justo, puede ser justificadamente identificado con la defensa de los derechos humanos).

Otro problema relevante para el tema de la fundamentación ética de los derechos humanos es el del alcance, jerarquía y límites de estos derechos. Ni el alcance, ni la jerarquía, ni los límites son los mismos para todos los derechos que contiene cualquier tabla contemporánea de los Derechos Humanos. En este punto es necesario establecer una graduación jerárquica entre los distintos derechos según su importancia, ordenada en relación con la idea de dignidad humana (la que aquí defiendo es, de mayor a menor importancia, los derechos personales y de seguridad, los derechos cívico-políticos y los derechos económicos-sociales). Como conclusión de esa jerarquización se instituye también una diferencia en el alcance y límites de los derechos humanos, de tal forma, por ejemplo, que un derecho humano personal, v. gr., derecho al honor, derecho a la libertad de conciencia, tenga un alcance más amplio y encuentre más dificultades para la limitación en su ejercicio que un derecho político, v. gr., derecho de asociación política. De todas formas, y en relación con lo anterior, no olvido que se pueden plantear dificultades y problemas a la hora de evaluar casos concretos y que esta valoración entre derechos responde a las concepciones de filosofía moral, política y jurídica de que se parta.

También de lo anterior podemos obtener la conclusión de que resulta casi imposible encontrar una única fundamentación ética válida para todos los derechos humanos, con la excepción de la idea de dignidad humana. A partir de ahí ya nos debemos centrar en el análisis de las diferentes fundamentaciones éticas según los distintos derechos. Como apuntó NoRBERTo BoBBIo hace unos años "no se debe hablar de un fundamento único, sino de fundamentos de los derechos del hombre, de fundamentos diferentes" (74).

Hasta ahora he identificado la fundamentación ética de los derechos humanos con los valores y exigencias éticas que respaldan estos derechos, y obviamente esos valores y exigencias éticas son el contenido de esa fundamentación. Sin embargo, ha llegado

(73) Elf́as DÍAz, Socialismo democrático y derechos humanos, en «Legalidad-legitimidad en el socialismo democrático», cit., pág. 25.

(74) NORBERTo BoBbIo, L'illusion du fondemet absolu, en "Le fondement des droits de l'homme», cit., pág. 6. 
la hora de preguntarnos por su razón de ser, por su misma racionalidad: ¿a qué tipo de valores nos referimos cuando hablamos de Derechos Humanos Fundamentales?, ¿de qué tipo de exigencias se trata?, ¿exigencias absolutas, universales, históricas, convencionales, mínimamente racionales o simples reflejos de una sensibilidad humanista y de la emotividad humana? Y, finalmente, ¿existen buenas razones para la defensa y justificación de los derechos humanos fundamentales?

Como esquema de lo que a partir de ahora desarrollaré, adelanto en relación con el primer interrogante que me refiero a los valores relativos a la dignidad humana, como valores de seguridad, libertad e igualdad. En relación con el segundo y tercer interrogante contesto que se trata de exigencias no absolutas (con la única excepción de la exigencia de respeto a la vida), históricas (defender la historicidad de estas exigencias no disminuye su importancia y necesidad) y también de exigencias racionales. Finalmente, en relación con el cuarto interrogante, defenderé la idea de que existen buenas razones para la justificación de los derechos humanos.

Comenzaré por contestar a los interrogantes segundo, tercero y cuarto, cuyo problema puede definirse como la posibilidad de elaborar una justificación racional de la fundamentación ética de los derechos fundamentales.

Esta justificación racional consta de tres pasos o requisitos:

1. Como primer requisito debemos partir de la constatación mínima o suposición, si se quiere, de que los derechos humanos son algo (ideales, exigencias, derechos) que consideramos deseable, importante y bueno para el desarrollo de la vida humana. (Si no aceptamos esta suposición no tiene sentido preguntarse por los derechos humanos ni por su fundamento.)

Si se nos pregunta por qué consideramos deseables, importantes y buenos los derechos humanos podríamos contestar (como último argumento) que su negación, no reconocimiento, ni respeto, ni garantía o la prohibición de su ejercicio pone en tela de juicio la idea de dignidad humana y hasta, por ejemplo, en el caso del derecho a la vida y a la integridad física y moral, la misma posibilidad de la vida, lo que contrastaría con el hecho comprobable y verificable intersubjetivamente de que en todas las sociedades conocidas la mayor parte de las personas prefieren vivir a no vivir y además desean un tipo de vida más rica y compleja que la que les daría la mera supervivencia física (75).

(75) La semejanza de esta idea con «el contenido mínimo del Derecho 
2. En un segundo momento, una vez admitido el primer requisito, se tratar:a de buscar el fundamento de cada uno de los derechos humanos, contando siempre con la convicción de que se tienen buenas razones para alegar a su favor (76).

Estas buenas razones nos conducen, en último término, a la justificación de valores últimos que deseamos como objetivos o ideales y que elegimos frente a su negación y por encima de otros valores más secundarios. La evaluación de esos valores y la elección entre ellos también puede ser decisiones racionales aptas para ser justificadas. La argumentación no puede llegar hasta el infinito, ni es esa mi intención, sin embargo, creo que respecto a la justificación final de los valores primarios o últimos se puede utilizar el método que señala HaNS ALBERT respecto a la comparación entre distintos sistemas éticos posibles: «la comparación entre distintos sistemas éticos posibles habrá que basarla en la experiencia, al igual que sucede cuando se trata de teorías científicas que versan sobre un mismo dominio. También los sistemas éticos, pueden ser más o menos verificados, si bien de distintas formas que la ciencia...

Natural" de que habla Hart es notable. Para Hart: «La reflexión sobre algunas generalizaciones muy obvias referentes a la naturaleza humana y al mundo en que los hombres viven, muestra que en la medida en que ellas sigan siendo verdaderas, hay ciertas reglas de conducta que toda organización social tiene que contener para ser viable...

Tales principios de conducta universalmente reconocidos, que tienen una base en verdades elementales referentes a los seres humanos, a su circunstancia natural y a sus propósitos, pueden ser considerados como el contenido mínimo del Derecho Natural, en contraste con las construcciones más grandilocuentes y más controvertibles que a menudo han sido enunciadas bajo ese nombre..

Al considerar las simples verdades obvias que expondremos aquí, y su conexión con el derecho y la moral, es importante observar que en cada caso los hechos mencionados suministran una razón para que, dada la supervivencia como objetivo, el derecho y la moral deben incluir un contenido específico. La forma general del argumento es simplemente que sin tal contenido las normas jurídica y la moral no podrían llevar a cabo el propósito mínimo de supervivencia que los hombres tienen al asociarse entre sín, en El concepto de Derecho, Editora Nacional, México, 1980, Trad. de Genaro R. Carrió, páginas 238 y 239.

También tiene puntos en común este primer paso con lo expresado por JOSÉ FERRATER MORA en su obra De la materia a la razón, Alianza Editorial, Madrid, 1979, págs. 174 y sigs. "Si se prefiere vivir a no vivir -escribe Ferrater Mora, pág. 175- es, pues, porque se supone que vivir es una realidad positiva, que merece ampliarse y respetarse.n

(76) Sobre este punto soy deudor de las ideas expresadas por NORBERTo Bоввіо en su artículo L'illusion du fondement absolu, ya citado, pág. 3. 
En cualquiera de los casos, a la hora de fijar un criterio para la verificación de los sistemas éticos habrá que poner en primer plano la satisfacción de las necesidades humanas, el cumplimiento de los deseos humanos, la eliminación del sufrimiento humano innecesario, la armonización de las aspiraciones humanas intrasubjetivas e intersubjetivas, hechos, en todos los casos, que son controlables sobre la base de experiencias humanas" (77).

3. El tercer paso se centraría: a) en la posibilidad de que esas buenas razones que alegamos puedan ser expresadas a otras personas, es decir, puedan ser objeto de diálogo y contrastación con las que otras personas argumenten también como buenas razones, y b) también se centraría en la posibilidad, como fruto de lo anterior, de que esas buenas razones obtuvieran un reconocimiento general o lo más general posible (78).

En definitiva, analizar el fundamento ético de los derechos humanos fundamentales es plantear también la posibilidad de la racionalidad y universalidad de ese fundamento, y hablar de racionalidad y universalidad del fundamento ético de los derechos humanos no es hablar de derechos absolutos, atemporales $e$ invariables, sino de derechos morales, que puedan ser justificados racionalmente (79) y cuenten con la pretensión de ser universalizados en un momento histórico concreto.

(77) HANs AlBerr, Etica y Metaética. El dilema de la filosofía moral analitica, Ed. Teorema, Valencia, 1978, trad. de Manuel Jiménez Redondo e introducción de Jesús Rodríguez Marín, pág. 4647.

(78) Ver Ch. Perelman, Peut-on fonder les droits de l'homme, en "Le fondement des droits de l'homme», cit., pág. 17.

Sobre la racionalidad, intersubjetividad y el consenso ver el diálogo entre HeRbert Marcuse y Jürgen Habermas, Teoría y politica, en Ed. Teorema, Valencia, 1980, trad. de Manuel Jiménez Redondo. También sobre la situación comunicativa ideal y la teoría consensual de la verdad en Habermas ver ENRIQUE M. UREÑA, La teoría critica de la sociedad de Habermas, Ed. Tecnos, Madrid, 1978, págs. 119 y sigs.; y RAÚL GaBAs, J. Habermas: dominio técnico y comunidad lingüística, Ed. Ariel, Barcelona, 1980, págs. 220 y sigs. Prólogo de Javier Muguerza.

«E1 intersubjetivismo - ha escrito J. Ferrater Mora- expresa simplemente el hecho de que una teoria, lo mismo que un programa práctico que contenga fines supersuficientes son propuestos a la consideración de todos los sujetos humanos con la aspiración a producir un consenso, incluyendo, una vez más, el consenso de admitir su carácter provisional y su revisabilidad", en De la materia a la razón, cit., pág. 171. También JAVIER MUGUERZA, La ética en la cruz del presente en "Enrahonar», Quaderns de Filosofía, Universitat Autónoma de Barcelona, Primer sem. 1981, págs. 7 y sigs.

(79) Ver el artículo de ENRIQue P. HaBA, Droits de l'homme, libertés individuelles et rationalité juridique. (Quelques remarques méthodologiques), ya citado, págs. 325 y sigs. 
La referencia al momento histórico o en general a las circunstancias históricas no carece de importancia para el tema de la fundamentación ética de los derechos humanos. Sólo así es posible no caer en la «ilusión del fundamento absoluto», en palabras de Norberto BobBio, como cayeron los teóricos del derecho natural racionalista de los siglos XVII y XVIII al fundar ciertos derechos, de manera irrefutable, presentándolos como derivados directamente de la naturaleza humana. El estudio de las condiciones históricas se torna indispensable para la fundamentación de los derechos humanos, pues son esas mismas consideraciones históricas las que dan sentido a la proclamación y a la posibilidad de realización auténtica de los derechos proclamados. Como ha señalado Norberto BoBBio "No se trata de encontrar el fundamento absoluto - proeza gloriosa, pero desesperada - se trata de encontrar los diversos fundamentos posibles. No obstante, de todas maneras está búsqueda de los fundamentos posibles -hazaña legítima y no condenada a la esterilidad como la otra- no tendrá ninguna importancia si no está acompañada del estudio de las condiciones, de los medios y de las situaciones, donde tal derecho o tal otro pueda ser realizado. Este estudio es la tarea de las ciencias históricas y sociales. El problema filosófico de los derechos del hombre no puede ser disociado del estudio de los problemas históricos, sociales, económicos, psicológicos, inherentes a su ejecución" (80).

Por mi parte solamente añadiría al texto de $\mathbf{N}$. Boвbio que esos fundamentos posibles, e históricos ya que se dan en la historia humana, de los derechos humanos deben ser justificados ética y racionalmente (81). en la línea de lo anteriormente expresado.

Pero volvamos al primer interrogante lanzado unas páginas más arriba, ¿a qué tipo de valores nos referimos cuando intentamos fundamentar éticamente los derechos del hombre y nos preguntamos por su misma razón de ser?, ¿cuáles serían esas exigencias racionales de la conciencia moral que nos permiten hablar de derechos humanos inalienables e inherentes al ser humano? (82).

Parece bastante correcto sostener que esos valores y exigen-

(80) N. Boввio, L'ilusion du fondement absolu, en «Le fondement des droits de l'homme», cit., pág. 9.

(81) Ver los artículos de CH. Perelman, Peut-on fonder les droits de thomme? y JOSEP H MOREAU, Les droits de l'homme: Déclarations et fondement, en «Le fondement des droits de l'homme», cit., págs. 10 y sigs. y 126 y siguientes, respectivamente.

(82) Ver AUguSto Guzzo, La conscience morale et les droits de l'homme, "Le fondement des droits de l'homme», cit. págs. 42 y sigs. 
cias morales y racionales giran en torno a la idea de dignidad humana, idea básica y condición sine qua non para hablar de derechos humanos fundamentales. Esa es la idea que aparece clara y prioritariamente expresada en el Preámbulo de la Declaración Universal de Derechos Humanos de la ONU (1948), cuando en el primer considerando se enuncia que «la libertad, la justicia y la paz en el mundo tienen por base el reconocimiento de la dignidad intrínseca y de los derechos iguales e inalienables de todos los miembros de la familia humana», y en el artículo 1. "Todos los seres humanos nacen libres e iguales en dignidad y derechos...». Y esa idea es la noción central, como ha apuntado JANos ToTH (83), de los distintos valores proclamados en dicha Declaración.

De la idea de dignidad humana se derivan unos valores que han de fundamentar los distintos derechos humanos. Estos valores son la seguridad, la libertad y la igualdad. El valor «seguridad" fundamenta los derechos personales y de seguridad individual y jurídica, el valor «libertad» fundamenta «los derechos cívico-políticos» y, finalmente, el valor "igualdad» fundamenta los derechos económicosociales y culturales. Veamos esto con más detenimiento.

A) Los derechos personales y derechos de seguridad responden al valor seguridad, son los más estrechamente enlazados con la idea de dignidad humana y expresan derechos de la persona considerada como individuo autónomo, libre y responsable. Sus contenidos son, como ha apuntado JosE CASTÁN TOBEÑAS, una "derivación de aquel derecho del hombre, verdaderamente primario y básico, que es el derecho a que sea reconocida y protegida su personalidad» (84).

(83) Janos Toth, comentando el primer texto citado, escribe: «Esta afirmación, colocada a la cabeza de la Declaración Universal de los Derechos del hombre, implica una revolución ética en la vida de la humanidad. La Declaración constituye un código de valores que están en la base de las relaciones humanas y motivan a los otros seres humanos que viven en sociedad. La conducta de los hombres debe estar amoldada y guiada por estos valores... La revolución consiste en el hecho de que la Declaración Universal es la primera que, tomando como base la dignidad humana, ha sido elaborada y adoptada para toda la humanidad con un alcance y una validez universal", en Les droits de l'homme et la theorie du droit, en René Cassin. Amicorum discipulorumque liber IV. Methodologie des droits de l'homme, Editions A. Pedone, París, 1972, págs. 76-77.

(84) José CASTÁN ToBeÑas, Los Derechos del Hombre, cit., pág. 37. También al respecto ha escrito Luis Legaz y Lacambra: "Hay un derecho absolutamente fundamental para el hombre, base y condición de todos los demás: el derecho de ser reconocido siempre como persona humana», en La noción juridica de la persona humana y de los derechos del hombre, "Revista de Estudios Políticos», vol. XXXV, Madrid, 1951, pág. 44. 
Me refiero aquí a los derechos a la vida y a la integridad física, a la libertad de conciencia y de pensamiento, al derecho al honor y a la fama, a las garantías procesales y a la legalidad de las penas, entre otros de semejante condición y naturaleza.

B) Del valor libertad se deducen, y encuentran en él (85) su fundamento, los derechos de libertad o derechos de la persona como ciudadano y miembro activo de la sociedad política o Estado. Estos derechos tienen su núcleo, con palabras de H. L. A. HART, en «el derecho igual de todos los hombres a ser libres» (86) e incluyen dos aspectos de la libertad que tradicionalmente se han denominado libertad negativa (87) y libertad positiva (88).

(85) Escribe Steven Lukes: «Considérese la pregunta: ¿cuándo es libre una persona? En mi opinión hay, por lo menos, tres respuestas fundamentales a esta cuestión, cada una de ellas parte indispensable de una contestación correcta.

La primera es que la persona es libre, en la medida en que sea dueña de sus actos, es decir, en la medida en que éstos procedan de decisiones y opciones de la persona como agente libre, y no como instrumento u objeto de la voluntad de otro o como resultado de fuerzas externas o internas independientes de su voluntad... / una segunda respuesta... lo será cuando se libere de interferencias y obstáculos, lo cual dependerá de la medida en que sus congéneres le permitan pensar y actuar como le plazca. Se trata del llamado sentido negativo de la libertad, que yo prefiero denominar un aspecto de la libertad / tercera respuesta... el hombre es libre en la medida en que pueda configurar el curso de su vida, realizando así sus potencialidades, es decir, aprovechando al máximo sus posibilidades», en «El individualismo», cit., páginas 157,158 y 159 , respectivamente.

(86) H. L. A. HART, ¿Existen derechos naturales? en «Filosofía política», recopilación de Anthony Quinton, Fondo de Cultura Económica, México, 1977, trad. de E. L. Suárez, pág. 84.

(87) «Entiendo por libertad en este sentido (libertad negativa) -escribe I. Berlín- el hecho de no ser obstaculizado por otros. Cuanto mayor sea la zona de no interferencia, mayor será mi libertad", "Dos conceptos de la libertad», en Filosofía politica, cit., pág. 218. «Bajo el nombre de libertad negativa se comprenderá, ante todo, la remoción de los obstáculos que se opongan al desarrollo y el aseguramiento de una esfera de independencia que haga posible tal desarrollo, que Hobbes considera como un fin atribuido al Estado», ha señalado A. Passerin D Entreves en La noción de Estado, cit., pág. 223.

(88) Para A. PASSERIN D'ENTREves: «La libertad positiva corresponde a la "libertad de los antiguos" y es algo totalmente distinto a la libertad negativa, sobre la que... insisten los autores liberales modernos. La libertad positiva implica posibilidad de determinar la propia suerte, capacidad de participar en el mando, libertad de darse leyes y de no obedecer más que a éstas. La libertad positiva postula la soberanía popular...», en La noción de Estado, cit., pág. 234. Para I. BERLfN: «El sentido positivo de la palabra libertad se deriva del deseo que tiene el individuo de ser su propio amo. Deseo que mi vida y mis decisiones, dependan de mí mismo, no de fuerzas externas de ninguna clase.» Dos conceptos de la libertad, en «Filosofía política», cit., págs. 228-229. 
Se trataría, por ejemplo, de los derechos a la libertad de expresión, de reunión y asociación y en general del derecho a la participación política.

C) Del valor igualdad se derivan los derechos de igualdad, fundamentalmente los derechos económico-sociales y culturales, es decir, derechos que amplían la idea de igualdad formal, dándole un nuevo sentido que la convierta, además, en igualdad sustancial (89).Se trataría de derechos de la persona como trabajador y creador de su entorno cultural.

La idea de igualdad, sin adjetivos, ha sido citada repetidamente en las declaraciones históricas sobre derechos humanos y sigue siendo invocada en textos contemporáneos. Pero generalmente suele ser mencionada de forma imprecisa, vaga y ambigua; por ello creo conveniente insistir, en honor a la claridad de lo que con este término se quiera significar, que deben precisarse dos puntos:

1. Que la defensa de la idea de igualdad como objetivo y valor moral no ignora el hecho comprobable de la existencia de seres desiguales en características biológicas, intelectuales y morales. Habría que decir que junto al hecho innegable de la existencia de seres desiguales, la idea de igualdad no pierde sentido, sino que lo adquiere. Como ha apuntado LoRD RoBBINS «la consideración de la igualdad como un objetivo es esencialmente ética y no fáctica» (90). También habría que precisar que la idea de igualdad no es identificable, aunque la pueda incluir con una postura favorable a un igualitarismo socio-económico.

2. Que existen distintos significados del término igualdad, que suelen estar implícitos cuando utilizamos este concepto, pero que generalmente no se expresan abiertamente y esto puede ser una fuente de errores. Estos distintos significados hacen referencia a las ideas de igualdad moral, igualdad ante la ley, igualdad de derechos cívico-políticos, igualdad de oportunidades e igualdad económica (91). Como es evidente los distintos significados que puede en-

Ver también Dino PasINI, Riflessioni sul problema della libertá negativa $e$ positiva, en «Problemi di Filosofia della politica», Casa Editrice Dotto. Eugenio Jovene, Napoli, 1977, págs. 99 y sigs.

(89) Debo muchas aclaraciones sobne este tema de la igualdad al profesor Antonio Enrique Pérez Luño, quien durante 1981 ha dictado un curso sobre «El concepto de igualdad como fundamento de los derechos económicos, so ciales y culturales, en el recientemente creado Instituto de Derechos Humanos de la Universidad Complutense.

(90) LORD ROBbINS, Libertad e igualdad, Unión Editorial, S. A., Madrid, 1980 , pág. 14.

(91) Ver LORD ROBBINS, Libertad e igualdad, cit., págs. 13 y sigs.; y MIGUEL 
volver la idea de igualdad son, en algunos casos, diferentes en grado sumo. Por ello me parece legítimo hacer hincapié en la necesidad de que cuando utilicemos el término igualdad se añada a qué tipo de igualdad nos referimos.

Cuando yo utilizo el término igualdad aquí como valor que fundamenta los derechos de igualdad quiero dar por supuestas las ideas de igualdad moral, jurídica y política (que estarían ya incluidas en los derechos personales y cívico-políticos) y centrarme con éxclusividad en los derechos económico-sociales y culturales, derechos que creo tienen que ver inexorablemente con la igualdad de oportunidades y que no tienen que ver necesariamente con la igualdad económica (entendida como igualdad de remuneración y de propiedad), aunque la existencia de extremas desigualdades económicas y sociales hacen irrealizable el efectivo ejercicio de los derechos económicos, sociales y culturales, como la historia se ha ocupado en demostrar con insistencia.

Los derechos económicos, sociales y culturales deducidos del valor igualdad entendido de esta manera serían, por ejemplo, el derecho al trabajo, a la seguridad social y a una remuneración justa, el derecho a la protección de la salud, los derechos de los consumidores y los derechos a la cultura y a la educación.

La clasificación de los derechos hasta aquí enumerados: derechos personales y de seguridad, derechos de libertad y derechos de igualdad, según los valores qeu los fundamentan, no quiere decir, en ningún caso, que cada uno de los distintos derechos sean compartimentos estancos con total autonomía. Una teoría contemporánea de los derechos humanos debe partir del hecho de la estrecha conexión y complemento de unos y otros. Los derechos personales y de seguridad son poca cosa sin los derechos cívico-políticos; la misma relación se podría establecer entre éstos y aquéllos y los derechos económicos-sociales y culturales. Creo que tiene razón ALFONSO NORIEGA cuando ha escrito que «Entre los derechos individuales y los sociales no existe contradicción, ni tampoco oposición, y por tanto, es artificial pretender que unos prevalezcan sobre los otros, o bien los segundos desplacen a los primeros» (92).

RODRIGUEZ-PIÑERo, El principio de igualdad y las relaciones laborales, número 121 de la «Revista de Política Social», Centro de Estudios Constitucionales, Madrid, 1979, págs. 381 y sigs.

(92) ALFONSo NoRIEGA, Los derechos humanos en México y problemas actuales que se plantean, en "Las experiencias del proceso político constitucional en México y España», Universidad Nacional Autónoma de México, 1979, página 414 
El ejercicio de la libertad, y en concreto de los derechos de libertad, es imposible e impensable sin una igualdad moral, jurídica y de oportunidades (93), tampoco puede ser efectivo ese ejercicio mientras y donde existan y persistan unas estructuras socio-económicas extremada y profundamente desiguales, pues en ese caso los derechos personales y políticos se convierten en algo casí vacío de contenido (94).

En este tema, y para finalizar, podemos añadir que es ejemplar al respecto el papel que la Constitución Española de 1978 asigna a los poderes públicos en su artículo 9.2: «Corresponde a los poderes públicos promover las condiciones para que la libertad y la igualdad del individuo y de los grupos en que se integra sean reales y efectivas; remover los obstáculos que impidan o dificulten su plenitud y facilitar la participación de todos los ciudadanos en la vida politica, económica, cultural y social» (95).

(93) Para un tratamiento contemporáneo de estos temas, ver JoHN RawLs, Teoría de la Justicia, Fondo de Cultura Económica, México, 1979, trad. de María Dolores González Soler, págs. 82 y sigs. y 227 y sigs.; RONALD DWORKIN, Taking Rights Seriously, Duckworth, London, 1977, págs. 150 y sigs., 184 y siguientes y 259 y sigs.; H. L. A. HART, Entre el principio de utilidad y los derechos humanos, en "Revista de la Facultad de Derecho de la Universidad Complutense de Madrid», núm. 58, 1980, págs. 7 y sigs., trad. de María Dolores González Soler, F. Laporta y L. Hierro.

(94). Ver E. F. CARRIT, La libertad y la igualdad, en «Filosofía Política», cit., págs. 195 y sigs.; STEVEN LuKes, El individualismo, cit., págs. 155 y siguientes; LORD ROBBINs, Libertad e igualdad, cit.

La Constitución de los Estados Unidos Mexicanos (5 de febrero de 1917) supo plasmar a la perfección este problema cuando en su Capítulo primero señala que la democracia no debe ser considerada "solamente como una estructura jurírica y un régimen político, sino como un sistema de vida fundado en el constante mejoramiento económico, social y cultural del pueblo»; y no es extraño al respecto que sea México, como nos ha recordado Alfonso Noriega, quien «tuvo la honra y también la gloria, de ser la primera nación en el mundo que consignó expresamente en una constitución política derechos sociales", en Alfonso NORIEGA, Los derechos humanos en México, en «Las experiencias del proceso político constitucional en México y España», cit., pág. 408.

Ver también su obra, La naturaleza de las garantias individuales en la Constitución de 1917, Universidad Nacional Autónoma de México 1967, y su artículo Las ideas jurídico-politicas que inspiraron las declaraciones de derechos en las diversas constituciones mexicanas, en "Veinte años de evolución de los derechos humanos», cit., págs. 67 y sigs.

(95) Ver GREgorio PECES-BARBA, La nueva Constitución española desde la Filosofía del Derecho, «Documentación administrativa», núm. 180, octubrediciembre 1978 , págs. 30-31. 